The most common type of malignancy affecting the upper aerodigestive tract is squamous cell carcinoma. Basaloid squamous cell carcinoma (BSCC) is a rarely seen, high-grade, bimorphic variant of squamous cell carcinoma, which displays distinct histological features. This entity was first described by Wain et al. in 1986. Since then, approximately 170 cases of head and neck basaloid squamous cell carcinoma have been reported. Tonsils are an uncommon site of occurrence of basaloid cell carcinoma. Only 10 cases of basaloid squamous cell carcinoma arising in the tonsils have been described in current English literature. Histopathologically, these carcinomas are characterised by the presence of a basaloid component in close association with squamous cell carcinoma. In this article, a case of BSCC of the tonsil is reported. The clinical and histopathological features of this tumour are discussed. Relevant literature has been reviewed and differential diagnosis of this tumour is discussed.

Key words: basaloid squamous cell carcinoma, tonsil.

\section{Basaloid squamous cell carcinoma of the tonsil: report of a case and review of the literature}

\author{
Deviprasad Shetty, Vijayalakshmi Subramaniam, Adarsha Herale, \\ Prema Saldanha, Mahaveer Jain
}

Yenepoya Medical College, Mangalore, India

\section{Introduction}

Basaloid squamous cell carcinoma (BSCC) is an uncommon aggressive variant of squamous cell carcinoma which has a predilection for the upper aerodigestive tract region. It was first described in 1986 by Wain et al. in the tongue, larynx and hypopharynx. The histopathological characteristic of this carcinoma is the close relationship between its basaloid component and squamous carcinoma [1]. Approximately 170 cases of BSCC of the head and neck have been reported [2]. Only 10 cases of BSCC arising in the tonsils have been reported in current English literature. We report a case of BSCC of the tonsil. The clinical and histopathological aspects of this tumour are discussed along with its management.

\section{Case report}

A 53-year-old male patient presented to the Otorhinolaryngology Outpatient Department with complaints of difficulty in swallowing (predominantly solids) for 3 months. It was insidious in onset and gradually progressive. The patient also complained of a foreign body sensation in the throat. There was no history of odynophagia, change in voice, fever or weight loss. He had a 40 pack-year history of cigarette smoking and was not an alcoholic. He was a known hypertensive well controlled with medication. Examination revealed an enlarged left tonsil which was crossing the midline. The posterior pillar could not be visualised. The tonsillar swelling had a smooth surface, was firm, nontender and did not bleed on touch. The right tonsil showed grade 2 hypertrophy. The posterior pharyngeal wall was normal. Indirect laryngoscopic examination was normal. There were no palpable cervical lymph nodes. Complete blood count and biochemical parameters were within normal ranges. Computed tomography scan of the neck revealed a homogeneously enhancing well-defined mass lesion measuring $3.4 \mathrm{~cm} \times 3 \mathrm{~cm} \times 3.2 \mathrm{~cm}$ arising from the left tonsillar fossa abutting the posterior aspect of the tongue and soft palate (Figs. 1, 2 and 3). Thoracic and abdominal computed tomographic scans were normal. Excision biopsy of the tonsil was done under general anaesthesia. During the surgery, the lesion did not adhere to the deeper tissue planes (muscular plane), which provided a favourable plane of dissection. Histopathological examination of the excised specimen showed lymphoid tissue (tonsillar) with an infiltrating neoplasm composed of masses of cells having small to medium sized nuclei with inconspicuous nucleoli and scanty to moderate cytoplasm. Keratin pearls were seen focally. Some of the masses showed a 'comedo pattern' with central necrosis in the tumour masses. In areas, the cells were larger, resembling squamous cells (Figs. 4 and 5). These features were consistent with basaloid squamous cell carcinoma. The patient was administered chemoradiation postoperatively. Follow-up of the patient was done after 1 year and he did not show 


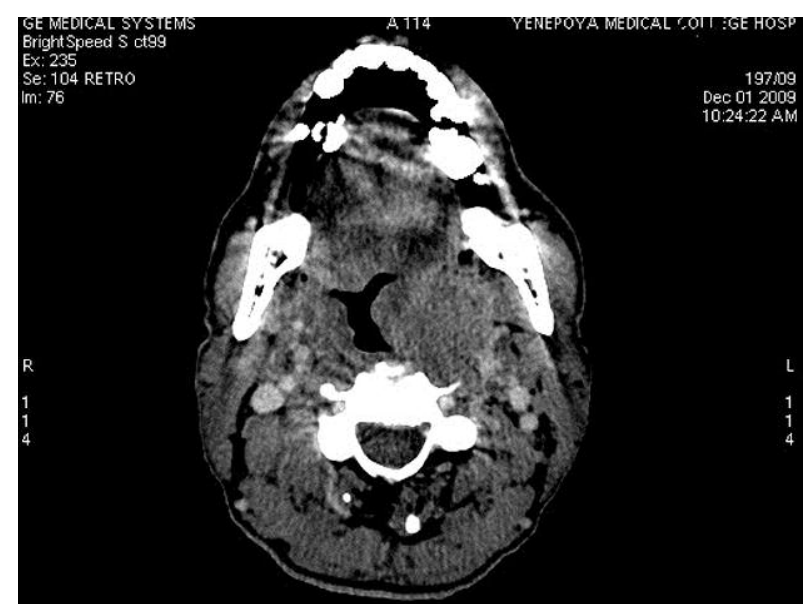

Fig. 1. Axial contrast enhanced computed tomographic scan showing homogeneously enhancing mass lesion measuring $3.4 \times 3 \mathrm{~cm}$ in the left tonsillar fossa

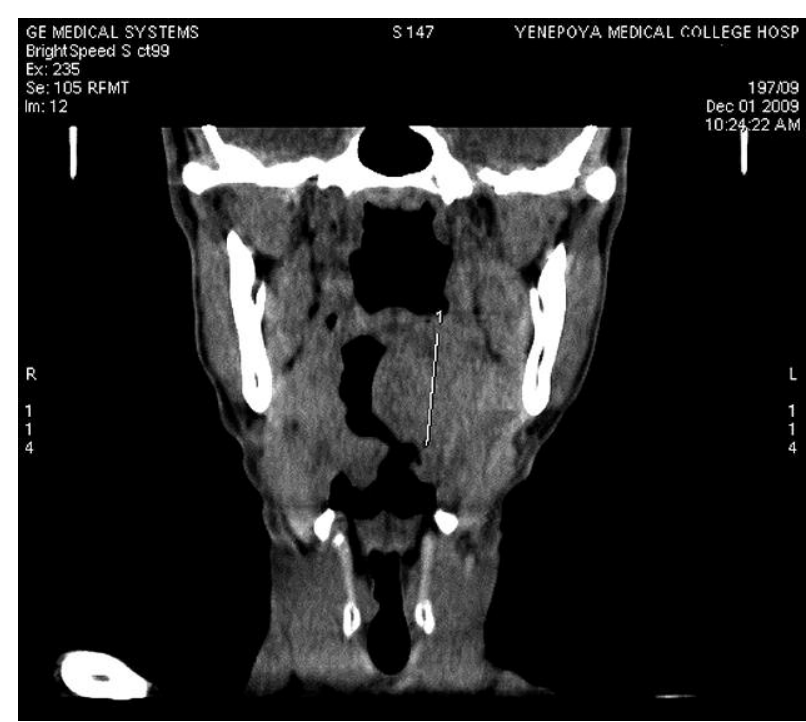

Fig. 2. Coronal computed tomography image of the oropharynx showing well-defined mass lesion arising from the left tonsillar fossa protruding into the oropharynx

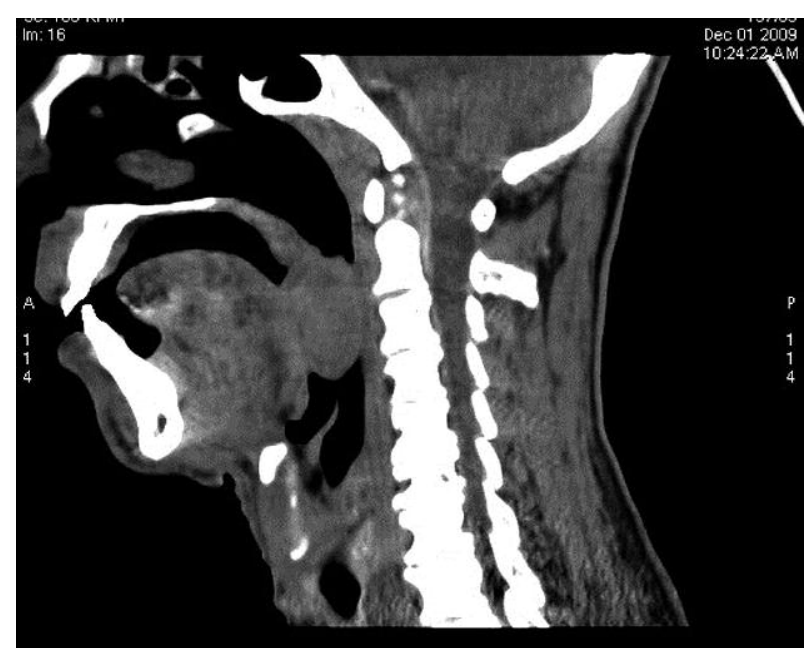

Fig. 3. Sagittal reconstruction showing mass arising from tonsillar fossa measuring $3.2 \mathrm{~cm}$ craniocaudally, abutting the posterior aspect of the tongue and soft palate any evidence of complications, local recurrence or distant metastasis.

\section{Discussion}

Basaloid squamous cell carcinoma is a rare and aggressive variant of squamous cell carcinoma with a strong predilection for the head and neck region. The upper aerodigestive tract is the most common site of origin of this tumour in the head and neck, especially the epiglottis, hypopharynx (piriform sinus) and base of the tongue. Other less common sites of origin in this region include the floor of the mouth, oral mucosa, palate, tonsils, sinonasal tract, nasopharynx, and trachea. Additionally, BSCC has been reported in the oesophagus, lung, anus, cervix uteri, penis and urinary bladder [3]. Since the first description of the histopathological entity by Wain et al. in 1986 [1], approximately 170 cases of head and neck BSCC have been described [2]. BSCC originating from the tonsils is uncommon, with only 10 cases having been described in current English literature [3-6].

$\mathrm{BSCC}$ is reported to occur in both sexes but predominates in males between 60 and 80 years old [7]. Alcohol and tobacco consumption are frequent antecedents. The possible relationship of BSCC and viruses is a matter of debate and has been reported in some locations including the nasopharynx and penis. The clinical signs and symptoms are not related to tumour location [3]. On physical examination, the tumour appears as an exophytic mass lesion that may have ulceration. Its physical characteristics do not diverge significantly from those of squamous cell carcinoma. Microscopic features are more specific and distinct [8].

Clinically, BSCC has been reported to be an aggressive tumour, often with an advanced clinical stage of disease at presentation, including extensive local invasion, multifocality, metastatic disease, and a short survival period. Aggressive behaviour characterised by perineural invasion, cervical lymph node metastases, and distant spread to lung, liver, bones, brain and skin has been observed [9].

Our patient was relatively young at 53 years and had no palpable cervical lymph nodes.

BSCC is believed to arise from multipotential primitive cells in the basal layer of the surface epithelium or from the salivary duct lining epithelium. The histopathological hallmark of this carcinoma is its basaloid pattern, intimately associated with squamous cell carcinoma, dysplasia or focal squamous differentiation. The basaloid component consists of growths of small, crowded cells in a lobular arrangement, closely opposed to the surface mucosa. These cells have dark hyperchromatic nuclei, scant cytoplasm and no nucleoli. Small cystic spaces containing mucinous-like material are interspersed within these lobules. Central coagulation necrosis within the lobules is seen regularly [1].

The two tumours that closely resemble BSCC histologically are adenoid cystic carcinoma (particularly the solid variant) and small cell undifferentiated (neuroendocrine) carcinoma. Foci of squamous carcinoma or dysplasia or in situ carcinoma in the overlying mucosa are characteristic of BSCC and are not seen in adenoid cystic carcinoma. Mitoses, nuclear pleomorphism and necrosis are prominent in BSCC and rare in adenoid cystic carcinoma (ACC). The clinical setting may also be of help because BSCC is often associated with pos- 


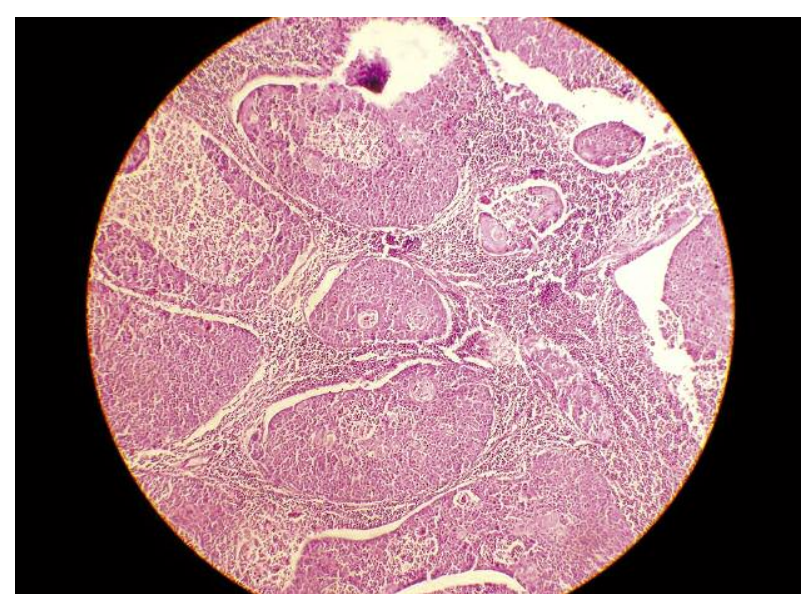

Fig. 4. Microphotograph showing lymphoid tissue (tonsillar) with an infiltrating neoplasm composed of masses of basaloid cells with peripheral palisading of cells (HE stain; 100x)

itive cervical lymph nodes at diagnosis while ACC is usually not. Small cell undifferentiated carcinoma can be distinguished from BSCC by the prominence of nuclear moulding, lack of stromal mucinous-myxoid changes and hyalinosis [8].

By immunohistochemistry, BSCC expresses cytokeratin and epithelial membrane antigen. Immunohistochemistry may be of help in diagnosis of small endoscopic biopsies in which only a partial view of the tumour is seen. Diagnosis of BSCC still remains on haematoxylin and eosin sections by recognising the typical diagnostic criteria defined by Wain et al. [3].

The possibility of finding a second primary tumour (either synchronous or metachronous) has to be borne in mind when diagnosing a BSCC in the head and neck. McKay and Bilous described a case of BSCC in the hypopharynx which showed in the surgical specimen a microinvasive squamous cell carcinoma in the left arytenoids region [10]. Seidman et al. have reported two cases of BSCCs arising in the pyriform sinus and vallecula associated with oesophageal small cell carcinoma and palatal squamous cell carcinoma respectively [11]. Wan et al. reported a BSCC of the nasal cavity in a patient who also had nasopharyngeal carcinoma [12]. Metachronous second primaries in the upper aerodigestive tract, bronchus and colon have also been reported [3]. In our patient, evaluation of the upper aerodigestive tract revealed no other malignancies. Abdominal and thoracic CT scans were normal as well, thus ruling out a second primary in the gastrointestinal and respiratory tract.

Surgical excision of the tumour followed by postoperative irradiation has been advised as an appropriate measure against local aggressiveness of the tumour, especially because of high mortality. Adjuvant chemotherapy has been recommended for prophylaxis against distant metastases [13]. This was advocated in our patient and he is in good health with no evidence of complications, local recurrence or distant metastases 1 year after surgery.

In conclusion, basaloid squamous cell carcinoma is an uncommon, high-grade bimorphic variant of squamous cell carcinoma with a predilection for the head and neck region. Although the base of the tongue, epiglottis and hypophar$\mathrm{ynx}$ are the most common locations, the entire upper

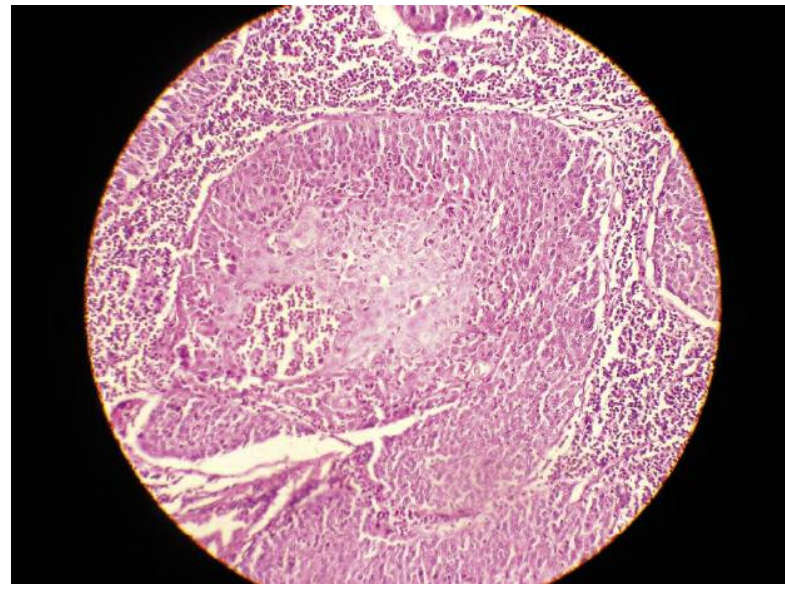

Fig. 5. Microphotograph of tumour mass showing a 'comedo pattern' with central necrosis in the tumour masses (HE stain; 200x)

aerodigestive tract is frequently affected. It appears similar to squamous cell carcinoma on macroscopic examination, but microscopic examination reveals its distinct and specific histological features. Diagnosis rests on haematoxylin and eosin sections by recognizing the typical histological criteria defined more than two decades ago. Distinguishing BSCC from other carcinomas is essential in order to plan therapy due to its more aggressive clinical behaviour. Complete surgical excision of the tumour supplemented with postoperative irradiation gives good local control while adjuvant chemotherapy offers prophylaxis against distant metastases.

The authors declare no conflict of interest.

\section{References}

1. Wain SL, Kier R, Vollmer RT, Bossen EH. Basaloid-squamous carcinoma of the tongue, hypopharynx, and larynx: report of 10 cases. Hum Pathol 1986; 17: 1158-66.

2. Zbären P, Nuyens M, Stauffer E. Basaloid squamous cell carcinoma of the hypopharynx. ORL J Otorhinolaryngol Relat Spec 2003; 65: 332-40.

3. Ereño C, Gaafar A, Garmendia M, Etxezarraga C, Bilbao FJ, López JI. Basaloid squamous cell carcinoma of the head and neck: a clinicopathological and follow-up study of 40 cases and review of the literature. Head Neck Pathol 2008; 2: 83-91.

4. Marioni G, Gaio E, Giacomelli L, Marchese-Ragona R, Staffieri C, Staffieri A, Marino F. Endoglin (CD105) expression in head and neck basaloid squamous cell carcinoma. Acta Otolaryngol 2005; 125 : 307-11.

5. Paulino AF, Singh B, Shah JP, Huvos AG. Basaloid squamous cell carcinoma of the head and neck. Laryngoscope 2000; 110: 1479-82.

6. Khurana KK, Powers CN. Basaloid squamous carcinoma metastatic to renal-cell carcinoma: fine-needle aspiration cytology of tumor-to-tumor metastasis. Diagn Cytopathol 1997; 17: 379-82.

7. Cardesa A, Zidar N, Ereño C. Basaloid squamous cell carcinoma. In: Pathology and genetics of head and neck tumours. Barnes L, Eveson JW, Reichart P, Sidrasky D (eds.); Kleihues P, Sobón LH (series eds.). World Health Organization classification of tumours. IARC Press; Lyon 2005; 124-5.

8. Eryilmaz A, Gocer C, Acar A, Dagli M, Albayrak L. Basaloid squamous cell carcinoma of the larynx. J Laryngol Otol 2002; 116: 52-3.

9. Coletta RD, Cotrim P, Vargas PA, Villalba H, Pires FR, de Moraes M, de Almeida OP. Basaloid squamous carcinoma of the oral cavity: report 
of 2 cases and study of AgNOR, PCNA, p53, and MMP expression. Oral Surg Oral Med Oral Pathol Oral Radiol Endod 2001; 91: 563-9.

10. McKay MJ, Bilous AM. Basaloid-squamous carcinoma of the hypopharynx. Cancer 1989; 63: 2528-31.

11. Seidman JD, Berman JJ, Yost BA, Iseri OA. Basaloid squamous carcinoma of the hypopharynx and larynx associated with second primary tumors. Cancer 1991; 68: 1545-9.

12. Wan SK, Chan JK, Tse KC. Basaloid-squamous carcinoma of the nasal cavity. J Laryngol Otol 1992; 106: 370-1.

13. Erdamar B, Suoglu Y, Sirin M, Karatay C, Katircioglu S, Kiyak E. Basaloid squamous cell carcinoma of the supraglottic larynx. Eur Arch Otorhinolaryngol 2000; 257: 154-7.

\section{Address for correspondence}

Dr. Vijayalakshmi Subramaniam

Assistant Professor

Department of ENT - Head and Neck Surgery

Yenepoya Medical College

Yenepoya University

Mangalore-575018

Submitted: 12.04 .2011

Accepted: $\quad 26.01 .2012$ 